\title{
Characteristics of Children Hospitalized with Infective Endocarditis at Dhaka Shishu Hospital
}

\author{
Rezoana Rima, Mohammad Abdullah Al Mamun \\ Department of Pediatric Cardiology, Bangladesh Institute of Child Health and \\ Dhaka Shishu (Children) Hospital.
}

\begin{abstract}
Key Words :
Abstract:

Children,

Infective

endocarditis,

Bangladesh

Background: The characteristics of infective endocarditis (IE) have significantly changed in pediatric age group during last few decades. The present study was conducted to study the clinical \& lab profile, risk factors, site of cardiac involvement and outcome of infective endocarditis in the largest children hospital of Bangladesh.

Methods: This prospective cross-sectional study was conducted in cardiology department with a diagnosis of IE from February 2014 to August 2016. Twenty-four children fulfilled the modified Duke diagnostic criteria.

Results: Definite IE was found in 58\% (14/24) patients, while the rest had possible IE. The most common presenting symptom was prolonged fever (> 2 weeks) \& heart murmur. Most commonly encountered risk factors included congenital heart disease (54\%), most commonly ventricular septal defect (21\%). Two patients (8.3\%) had history of rheumatic heart disease. Other important risk factors include post cardiac surgery (16.7\%), prolonged ICU stay of neonates (20.8\%). Nineteen patients (79\%) were classified as having culture-negative endocarditis and five (21\%) as culture positive. The most frequently isolated organisms were streptococci and followed by staphylococci and candida. Fifteen (62.5\%) patients had right-sided cardiac involvement. Seven (29\%) patients died of endocarditis or its complications.

Conclusion: Clinicians should have a high index of suspicion of endocarditis in persistently febrile patients with congenital heart disease and send blood cultures or refer appropriately before prescribing antibiotics.
\end{abstract}

(Cardiovasc. j. 2019; 12(1): 33-39)

\section{Introduction:}

Infective endocarditis (IE) is a continuously evolving disease with a persistently high morbidity and mortality. IE occurs less commonly in children than in adults, accounting for 1 in every 1300 to 2000 pediatric admissions annually. ${ }^{1,2}$ Although the reported hospitalization rates for IE vary considerably among published series, the frequency of endocarditis among children seems to have increased in recent years. ${ }^{3}$ This is due in part to improve survival among children who are at risk for endocarditis, such as those with congenital heart disease (CHD) and hospitalized newborn infants. An increasing proportion of children with IE have had previous corrective or palliative surgery for CHD, with or without implanted vascular grafts, patches, devices or prosthetic cardiac valves. , $^{3,4-7}$

Developing countries have a higher incidence of 'culture negative IE \& occurs in relatively young patients with underlying rheumatic and congenital heart diseases. ${ }^{8-11}$ The higher incidence of "culture negative endocarditis' largely secondary to prior doctor-prescribed or self administered antibiotic use $^{12,13}$ and life-threatening complications from IE are still common despite echocardiographic diagnosis and use of effective antibiotics. ${ }^{14}$

The purpose of our study was to assess the characteristics of children with IE including the clinical \& laboratory profile, risk factor, site of

Address of Correspondence : Dr. Rezoana Rima, Department of Pediatric Cardiology, Bangladesh Institute of Child Health and Dhaka Shishu (Children) Hospital, Dhaka, Bangladesh. E-mail: drrezoana@gmail.com

(C) 2018 authors; licensed and published by International Society of Cardiovascular Ultrasound, Bangladesh Chapter and Bangladesh Society of Geriatric Cardiology. This is an Open Access article distributed under the terms of the CC BY NC 4.0 (https://creativecommons.org/licenses/by-nc/4.0). 
cardiac involvement and outcome in the current era in hospitalized children of Dhaka Shishu Hospital.

\section{Methods:}

All patients referred to the Department of Pediatric Cardiology of Dhaka Shishu (Children) Hospital with the presumptive diagnosis of infective endocarditis were enrolled prospectively over a period of almost 31 months between February 2014 to August 2016. We used the modified Duke criteria ${ }^{15}$ in order to validate our results. Cases were defined clinically as "definite" if they fulfilled two of the Duke major criteria, one major plus three minor criteria, or five minor criteria; they were defined as "possible" if they fulfilled one major plus one minor criteria, or three minor criteria.

Demographic data and base-line characteristics were collected and a structured history was taken. Specific attention was paid to potential risk factors, which included a history of previous rheumatic fever or valvular heart disease, congenital heart disease, cardiac surgery (corrective or palliative surgery for CHD, with or without implanted vascular grafts, patches, or prosthetic cardiac valves), percutaneously implanted devices or other potential risk factors such as prolong ICU stay. During the physical examination, the presence or absence of any vascular or immunological phenomena (as defined by the Duke criteria) were actively sought and documented. During the primary evaluation, three blood cultures were taken from three different sites, within 24 hours. Any exposure to oral or intravenous antibiotics during the two days prior to the attainment of blood cultures was documented. In affected cases, Bactec Aerobic was used. All patients were examined by transthoracic echocardiography (TTE) using Vivid E9. Parasternal long- and short-axis windows, as well as apical fourand two-chamber views, were used to obtain twodimensional evaluations, M-mode dimensions and duplex Doppler studies. Vegetation was defined according to the Duke criteria. Further investigations included inthe primary diagnostic evaluation as a full blood count, C-reactive protein (CRP), Rheumatoid factor (RF), urinalysis (urine dipsticks and microscopy). Cultures and antimicrobial susceptibility testing guided the choice of antibiotics, whereas empirical therapy was given to culture-negative cases. Twenty-four patients were identified according to the modified Duke criteria, fifty -eight percent of patients had definitive endocarditis according to the Duke criteria while the rest had possible endocarditis.

\section{Results:}

Mean patient age was $05 \pm 4.2$ years (range, 22 days to 12 years), and $6(25 \%)$ patients were $<6$ months of age, $8(33 \%)$ patients were between 1 year to 5 years, $10(42 \%)$ patients were $>6$ years of age (Table-I). Four of the under six months patients were neonates. Male female ratio was 1.4:1. All the 24 patients admitted to Dhaka Shishu hospital with different referral diagnosis. Fourteen patients (58\%) were referred as pyrexia of unknown origin, six patients $(25 \%)$ as heart failure, two patients $(8.3 \%)$ had features of acute leukaemia. Only six patients (37.5\%) out of 16 patients with pyrexia of unknown origin \& patient having features of acute leukaemia suspected to have underlying heart disease. Two neonates presented with feeding difficulties, recurrent seizure (Table II). Overall, the most common presenting symptom was fever $(21 / 24$, $87.5 \%)$. Mean duration of fever was $42 \pm 35$ days. Seventy- five percent of all febrile patients had prolonged fever ( $>2$ weeks) prior to the diagnosis. Mean recorded temperature was $101.8^{0} \pm 1.99^{0} \mathrm{~F}$. Heart murmur was present in almost all patients (95.8\%). Clubbing was present in 5 patients (21\%), splenomegaly in 16 patients $(66.7 \%)$. The classic signs of IE, such as Janeway lesions, splinter hemorrhage, Roth spots and purpura were noted in only 6 (25\%) of our patients (Table-III).

Table-I

Age distribution of study population (N=24).

\begin{tabular}{lcc}
\hline Age & Number & Percent \\
\hline$<6$ months & 6 & 25.0 \\
1 year-5 years & 8 & 33.3 \\
6 years \& above & 10 & 41.7 \\
\hline Total & 24 & 100.0 \\
\hline
\end{tabular}

Mean age $5 \pm 4.2$ years (range 22 days to 12 years)

Table-II

Distribution of referral diagnosis $(N=24)$.

\begin{tabular}{lcc}
\hline Referral Diagnosis & Number & Percent \\
\hline Suspected Leukemia & 2 & 8.3 \\
Pyrexia of unknown origin & 14 & 58.3 \\
$\quad$ Suspected CHD & 2 & \\
$\quad$ Operated CHD & 4 & \\
$\quad$ Undetected CHD & 6 & \\
$\quad$ Absent CHD & 2 & \\
Heart failure & 5 & 20.8 \\
$\quad$ Suspected CHD & 4 & \\
$\quad$ Absent CHD & 1 & \\
Septicaemia+HF & 1 & 4.2 \\
Feeding difficulty \& recurrent & 2 & 8.3 \\
seizure & & \\
\hline
\end{tabular}


Table-III

Distribution of presenting features (multiple response) $(N=24)$.

\begin{tabular}{lcc}
\hline Presenting feature & Number & Percent \\
\hline Fever & 23 & 95.8 \\
Heart murmur & 23 & 95.8 \\
Clubbing & 5 & 21 \\
Hepatomegaly & 16 & 66.7 \\
Splenomegaly & 2 & 8.3 \\
Janeway lesion & 3 & 12.5 \\
Splinter hemorrhage & 1 & 4.2 \\
Roth spot & 1 & 4.2 \\
Purpura & 1 & 4.2 \\
\hline
\end{tabular}

Mean duration of fever $42.5 \pm 35.1$ days

Mean recorded temperature $101.8^{0} \pm 1.99^{0} \mathrm{~F}$

Overall, 22 patients (92\%) had an underlying predisposing factor (Table-IV). Most commonly encountered risk factors included congenital heart disease (45.8\%), most commonly a ventricular septal defect (21\%). Other important CHD were patent ductus arteriosus (8.3\%), bicuspid aortic valve (8.3\%), Tetralogy of Fallot (4.2\%), and stenotic pulmonary valve disease (4.2\%). Two patients (8.3\%) had history of rheumatic heart disease. Other important risk factors include post cardiac surgery (16.7\%), prolonged ICU stay (20.8\%) [Table-IV]. Four of five prolong ICU stay patients were neonates. Only one of them had undergone ductal stenting, others did not have any invasive procedures or central lines.

Table-IV

Distribution of risk factors.

\begin{tabular}{lcc}
\hline $\begin{array}{l}\text { Predisposing/ } \\
\text { risk factors }\end{array}$ & $\begin{array}{c}\text { Frequency } \\
\text { (number) }\end{array}$ & Percentage \\
\hline $\begin{array}{l}\text { Underlying congenital } \\
\text { heart disease }\end{array}$ & 11 & 45.8 \\
$\quad$ Ventricular septal & 5 & 21 \\
$\quad$ defect (VSD) & & \\
$\quad$ Patent ductus arteriosus & 2 & 8.3 \\
$\quad$ (PDA) & 1 & 4.2 \\
$\quad$ Pulmonary stenosis (PS) & 1 & 8.3 \\
$\quad$ Bicuspid aortic valve & 2 & 4.2 \\
$\quad$ Tetralogy of Fallot (TOF) & 1 & 8.3 \\
Rheumatic heart disease & 2 & 16.7 \\
Post cardiac surgery & 4 & 20.8 \\
Prolonged ICU stay & 5 & 8.3 \\
Unidentified & 2 & \\
\hline
\end{tabular}

Laboratory data showed that $79 \%$ had a raised CRP, while only $54 \%$ of patients were found to have an abnormally high white cell count, $45.8 \%$ patients have thrombocytopenia, $87.5 \%$ have anemia, $12.5 \%$ cases tested positive for rheumatoid factor, and none of these patients was known or suspected to have rheumatoid arthritis. Blood culture was positive in $21 \%$ patients \& causative microorganisms included streptococci (8.3\%), staphylococci (4.2\%) \& candida (8.3\%). Nineteen subjects $(79 \%)$ had no growth on multiple blood cultures and were thus classified as culture-negative IE (Table-V).

Table-V

Distribution of Laboratory data (multiple response).

\begin{tabular}{lcc}
\hline Laboratory data & $\begin{array}{c}\text { Frequency } \\
\text { (number) }\end{array}$ & Percentage \\
\hline Anaemia & 21 & 87.5 \\
Leukocytosis & 13 & 54 \\
Raised CRP & 19 & 79 \\
Thrombocytopenia & 11 & 45.8 \\
Rheumatoid factor & 3 & 12.5 \\
Blood culture positive & 5 & 21 \\
$\quad$ Streptococci & 2 & 8.3 \\
$\quad$ Staphylococci & 1 & 4.2 \\
Candida & 2 & 8.3 \\
\hline
\end{tabular}

Antibiotic therapy before hospital admission was $96 \%$ with $54 \%$ patient got oral antibiotics and $42 \%$ patient got parenteral antibiotics. Vegetation was detected in all patients by transthoracic echocardiography. Mean vegetation size was $11.3 \pm 5.3 \mathrm{~mm}$ (range 3 - 22 $\mathrm{mm})$. Fifteen patients (62.55\%) had vegetation in right side of heart, mostly in pulmonary valve (37.5\%). Eight patients (33\%) had vegetation in left side of heart mostly in mitral valve (Table-VI).

Table-VI

Distribution of site of vegetation $(N=24)$.

\begin{tabular}{lcc}
\hline Site of vegetation & $\begin{array}{c}\text { Frequency } \\
\text { (number) }\end{array}$ & Percentage \\
\hline Tricuspid valve & 6 & 25 \\
Pulmonary valve & 9 & 37.5 \\
Mitral valve & 5 & 20.8 \\
Aortic valve & 3 & 12.5 \\
Near repair (patch) site & 1 & 4.2 \\
\hline
\end{tabular}

Vegetation size Mean \pm SD $11.3 \pm 5.3$ mm (range 3-22 $\mathrm{mm}$ )

Antimicrobials were administrated to all patients. Eighty three percent patients received 4-6 weeks of antimicrobial therapy. In addition, one patient also underwent surgical interventions. Forty- two percent of patients were treated with a combination of ceftriaxone plus an aminoglycoside (gentamicin) and vancomycin. Vegetation resolved in 7 patients $(29 \%)$, one more patient it decreased in size (Table-VII). 
Table-VII

Treatment of the study population $(N=24)$.

\begin{tabular}{llcc}
\hline Treatment & & $\begin{array}{c}\text { Frequency } \\
\text { (number) }\end{array}$ & Percentage \\
\hline Antibiotics & Ceftriaxone +aminoglycoside (gentamicin)+vancomycin & 10 & 41.7 \\
& Meropenem+aminoglycoside (gentamicin)+vancomycin & 10 & 41.7 \\
& Other combination & 4 & 16.7 \\
Surgery & & 1 & 4.2 \\
\hline
\end{tabular}

Table-VIII

Distribution of complications and outcome.

\begin{tabular}{llcc}
\hline & & Frequency (number) & Percentage \\
\hline Complications & Acute kidney injury & 2 & 8.3 \\
& Acute cerebral infarct & 1 & 4.2 \\
& Multiple pneumatocele of lung & 1 & 4.2 \\
Outcome & Improved & 12 & 50.1 \\
& Discharged against medical advice & 5 & 20.7 \\
& Died & 7 & 29.2 \\
\hline
\end{tabular}

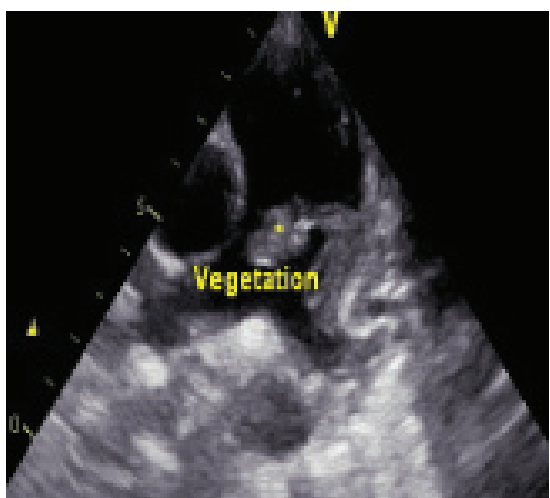

Fig.-1: showed large vegetation attached to pulmonary artery in a patient with PDA.

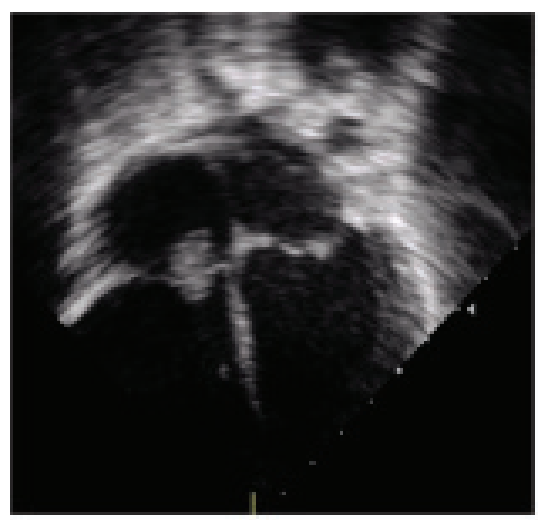

Fig.-2: showed large vegetation attached to tricuspid valve in a patient with VSD.
Complications occurred in about $25 \%$ of the study group and included acute kidney injury (8.3\%), acute cerebral infarct (4.2\%), multiple pneumatocele of lung (4.2\%), pneumonia (8.3\%). The total in hospital mortality in patients with IE was 7 (29.2\%) [TableVIII].

\section{Discussion:}

Infective endocarditis can be a lethal and devastating disease in children. Although IE occurs less commonly in children than in adults, the incidence of IE in children appears to have increased in recent years, especially among those with predisposing risk factors.1, 6, 16-18 Because of the increased survival rate of children with CHD; CHD now constitutes the predominant underlying condition for IE in children over the age of 2 years. The complexities of management of neonatal and pediatric intensive care unit patients have increased the risks of IE. In addition, postoperative IE is a long-term risk after correction of complex CHD.

Day et al. ${ }^{18}$ in a large national sample of hospitalized children showed that the median age at hospitalization was 12 years (range, 1 day to 20 years); the age distribution was bimodal, with peaks in infancy (31 days to 11 months of age) and the late teenage years (17 to 20 years of age). In our 
study $25 \%$ of patients were $<6$ months of age, $33 \%$ patients were between 1 year to 5 years, $42 \%$ patients were $>6$ years of age.

A male: female ratio of 1.4 in our analyses confirms the male predominance in infections in general and IE specifically. ${ }^{7,} 19,20$ In our series, $58 \%$ of our patients met the Modified Duke criteria as definite IE and $42 \%$ possible IE. This is comparable to $71 \%$ of definite and $29 \%$ of possible IE previously reported in Taiwan. ${ }^{21}$

According to published data, $10 \%$ or more of patients with definite IE do not have an audible cardiac murmur, ${ }^{22-25}$ whereas 23 of 24 patients enrolled in our study presented with a cardiac murmur on auscultation. The reasons for this discrepancy may reflect the differences in epidemiology and risk factor profile of our patients. Prior reports have suggested that endocarditis is occurring in fewer children with rheumatic heart disease, commensurate with its declining prevalence, and in a greater proportion of children without preexisting heart disease. 1,5,6,2627 These secular trends continued in our present analysis, in which only $8.3 \%$ had rheumatic heart disease but the percent of admissions without preexisting heart disease was $20.8 \%$ perhaps related toneonates \& infants with prolonged ICU stay with usage of multiple antibiotics.

Ventricular septal defect, patent ductus arteriosus, aortic valve abnormalities, and tetralogy of Fallot are reported to be common underlying conditions for IE. ${ }^{1,28-31}$ In this study, ventricular septal defect was the most frequent underlying condition with patent ductus arteriosus and aortic abnormalities lower than in previous reports. ${ }^{28,29}$

Out of 16 patients, only six patients (37.5\%) with pyrexia of unknown origin (PUO) \& patient having features of acute leukaemia, suspected to have underlying heart disease. This observation signifies the importance of detail physical examination especially precordium examination of any child with PUO.

Echocardiography has proved as the most important tool in establishing diagnosis of IE in our study. This was especially due to the low culture positivity rates. Vegetation was detected by transthoracic Echo (TTE) in all patients.

In children with CHD, right sided IE is reported to be more frequent than left sided, but in adults mainly with acquired heart disease, left sided IE is more prevalent. ${ }^{32}$ Our study also showed $62.5 \%$ patient had developed vegetation in right sided cardiac structures.

Prior antibiotic therapy before clinical presentation seen in $96 \%$ of our study group compared to $52 \%$ reported from largest case series of IE from Pakistan by Tariq $\mathrm{M}$ et al. ${ }^{33}$ which was the primary contributor to the high incidence (79\%) of negative blood cultures in our series. This incidence is consistent with the low yield from blood cultures, ranging from 21 to $67 \%$, reported from elsewhere on the subcontinent. ${ }^{14,34-36}$ In contrast, studies from industrialized counties report a diagnostic yield from blood cultures as high as $90 \%$ or more. ${ }^{36-39}$

The mortality rate in our study (29\%) was higher to that reported in the adult population ( $18 \%$ to $23 \%)^{40,41}$ or in recent pediatric IE series from large clinical centers caring for children with the most complex forms of CHD (10\% to $11 \%))^{5,6,42}$ This significantly higher mortality may be related to uncorrected congenital heart disease, excessive and improper use of antibiotics, late clinical presentation.

\section{Conclusion:}

Most common presenting symptoms of IE in children are prolonged fever \& heart murmur. Uncorrected congenital heart disease is the major predisposing factor. The mortality rate is much higher than recent international figures. Culturenegative endocarditis continues to have a high occurrence largely due to prior antibiotic use before clinical presentation. Clinicians should have a high index of suspicion of endocarditis and send blood cultures or refer appropriately before prescribing antibiotics.

\section{Conflict of Interest - None.}

\section{References:}

1. Ferrieri P, Gewitz MH, Gerber MA, Newburger JW, Dajani AS, Shulman ST, et al. Unique features of infective endocarditis in childhood. Pediatrics 2002;109:931-943.

2. Ako J, Ikari Y, Hatori M, Hara K, Ouchi Y. Changing spectrum of infective endocarditis: review of 194 episodes over 20 years. Circ $J$ 2003;67:3-7.

3. Stull TL, Li Puma JJ. Endocarditis in children. In: Kaye D, editor. Infective Endocarditis. 2nd ed. New York, NY: Raven Press; 1992:313-27. 
4. Baltimore RS. Infective endocarditis. In: Jenson HB, Baltimore RS, editors. Pediatric Infectious Diseases: Principles and Practice. Norwalk, Conn: Appleton \& Lange; 1995.

5. Saiman L, Prince A, Gersony WM. Pediatric infective endocarditis in the modern era. J Pediatr 1993; 122: 847-853.

6. Martin JM, Neches WH, Wald ER. Infective endocarditis: 35 years of experience at a children's hospital. Clin Infect Dis 1997; 24: 669-675.

7. Morris CD, Reller MD, Menashe VD. Thirty-year incidence of infective endocarditis after surgery for congenital heart defect. JAMA 1998;279: 599-603.

8. Garg N, Kandpal B, Garg N, Tewari S, Kapoor A, Goel $\mathrm{P}$, et al. Characteristics of infective endocarditis in a developing country - clinical profile and outcome in 192 Indian patients, 1992-2001. Int J Cardiol 2005; 98: 253260 .

9. Choudhury R, Grover A, Varma J, Khattri HN, Anand IS, Bidwai PS, et al. Active infective endocarditis observed in an Indian hospital 1981-1991. Am J Cardiol 1992; 70: 1453-1458.

10. Jalal S, Khan KA, Alai MS, Jan V, Iqbal K, Tramboo NA, et al. Clinical spectrum of infective endocarditis: 15 years experience. Indian Heart $J$ 1998; 50: 516-519.

11. Agarwal R, Bahl VK, Malaviya AN. Changing spectrum of clinical and laboratory profile of infective endocarditis. J Assoc Physicians India 1992; 40: 721-723.

12. Hafeez A, Kiani AG, ud Din S. Prescription and dispensing practices in public sectorhealth facilities in Pakistan: survey report. J Pak Med Assoc 2004;54:187191.

13. Siddiqi S, Hamid S, Rafique G. Prescription practices of public and private healthcare providers in Attock District of Pakistan. Int $J$ Health Plan Manage 2002;17:23-40.

14. Tariq M, Alam M, Munir G, Khan MA, Smego RA Jr. Infective endocarditis: a five-yearexperience at a tertiary care hospital in Pakistan. Int J Infect Dis 2004; 8:163-170.

15. Li J S, Sexton D J, Mick N, Nettles R, Fowler V G, Jr . Ryan T, Bashore T, Corey G R. Proposed Modifications to the Duke Criteria for the Diagnosis of Infective Endocarditis. Clinical Infectious Diseases 2000; 30:633638.

16. 16.Ashkenazi S, Levy O, Blieden L. Trends of childhood infective endocarditis in Israel with emphasis on children under 2 years of age. Pediatr Cardiol 1997; 18: 419e24. ( (

17. Rosenthal LB, Feja KN, Levasseur SM, Alba LR, Gersony W, Saiman L. The changing epidemiology of pediatric endocarditis at a children's hospital over seven decades. Pediatr Cardiol 2010; 31: 813e20.

18. Day MD, Gauvreau K, Shulman S, Newburger JW. Characteristics of children hospitalized with infective endocarditis. Circulation 2009; 119: 865e70.
19. Stockheim JA, Chadwick EG, Kessler S, Amer M, Abdel-Haq N, Dajani AS, et al. Are the Duke criteria superior to the Beth Israel criteria for the diagnosis of infective endocarditis in children? Clin Infect Dis 1998; 27:1451-1456.

20. Milazzo AS Jr, Li JS. Bacterial endocarditis in infants and children. Pediatr Infect Dis J 2001; 20:799-801.

21. Lin Y T, Hsieh K S, Chen Y S, Huang I F, Cheng M F. Infective endocarditis in children without underlying heart disease. J Microbiol Immunol Infect 2013; 46: 121-128.

22. Harris SL. Definitions and demographic characteristics. In: Kaye D, ed. Infective Endocarditis. New York, Raven Press, 1992:1.

23. Watankunakorn $\mathrm{C}$, Burkert T. Infective endocarditis at a large community teaching hospital, 1980-1990. Medicine 1993; 72:90.

24. Garvey GJ, Neu HC. Infective endocarditis: an evolving disease. Medicine 1978; 57:105.

25. Lien EA, Solberg CO, Kalager T. Infective endocarditis 1973-1984 at the Bergen University Hospital: Clinical feature, treatment and prognosis. Scand J Infect Dis 1988; 20:239-246.

26. Van Hare GF, Ben-Shachar G, Liebman J, Boxerbaum B, Riemen- schneider TA. Infective endocarditis in infants and children during the ( past 10 years: a decade of change. Am Heart $J$ 1984; 107:1235-1240.

27. Yoshinaga M, Niwa K, Niwa A, Ishiwada N, Takahashi $\mathrm{H}$, Echigo S, et al. Risk factors for in-hospital mortality during infective endocarditis in patients with congenital heart disease. Am J Cardiol 2008; 101:114-118.

28. Awadallah SM, Kavey R-EW, Byrum CJ. The changing pattern of infective endocarditis in childhood. Am J Cardiol 1991; 68: 90-94.

29. Fukushige J, Igarashi H, Ueda K. Spectrum of infective endocarditis during infancy and childhood: 20-year review. Pediatr Cardiol 1994; 15:127-131.

30. Gersony WM, Hayes CJ, Driscoll DJ. Bacterial endocarditis in patients with aortic stenosis, pulmonary stenosis, or ventricular septal defect. Circulation 1993; 87(Suppl I):I121-126.

31. Stanton BF, Baltimore RS, Clemens JD. Changing spectrum of infective endocarditis in children. Am J Dis Child 1984; 138:720-725.

32. Durack DT, Kaplan EL, Bisno AL. Apparent failures of endocarditis prophylaxis: analysis of 52 cases submitted to a national registry. JAMA 1983; 250:2318-2322.

33. Tariq M, Siddiqui B K, Jadoon A, Alam M, Khan S A, Atiq M, et al. Clinical Profile and Outcome of Infective Endocarditis at the Aga Khan University Hospital. Int $J$ Collab Res Intern Med Public Health 2009; 1(No. 3): 84-99. 
34. Sadiq M, Nazir M, Sheikh SA. Infective endocarditis in children - incidence, pattern, diagnosis and management in a developing country. Int J Cardiol 2001; 78:175182 .

35. Agarwal RK, Gupta R, Agarwal SC, Dwivedi M. Bacterial endocarditis - its diagnostic problems. J Assoc Physicians India 1981; 29:745-750.

36. Netzer RO, Zollinger E, Seiler C, Cerny A. Infective endocarditis: clinical spectrum, presentation and outcome. An analysis of 212 cases 1980-1995. Heart 2000; 84:25-30.

37. Hoen B, Alla F, Selton-Suty C. Changing profile of infective endocarditis: results of a 1-year survey in France. JAMA 2002; 288:75-81.
38. Cabell CH, Jollis JG, Peterson GE. Changing patient characteristics and the effect on mortality in endocarditis. Arch Intern Med 2002; 162:90-94.

39. 39. Prendergast BD. The changing face of infective endocarditis. Heart 2006; 92:879-885.(

40. Mylonakis E, Calderwood SB. Infective endocarditis in adults. N Engl J Med 2001; 345:1318-1330.

41. Delahaye F, Wong J, Mills PG. Infective endocarditis: a comparison of international guidelines. Heart 2007; 93:524-527.

42. Coward K, Tucker N, Darville T. Infective endocarditis in Arkansan children from 1990 through 2002. Pediatr Infect Dis J 2003; 22: 1048-1052. 